\title{
Furniture Sales Application with Android-Based Qr Code Technology (Case Study "99" Furniture Store)
}

\section{Aplikasi Penjualan Mebel Dengan Teknologi Qr Code Berbasis Android (Studi Kasus Toko "99" Mebel)}

\author{
Muhammad Dzikri Ramadhan ${ }^{1}$, Mohammad Suryawinata ${ }^{2}$ \\ \{161080200086@umsida.ac.id ${ }^{1}$, suryawinata@umsida.ac.id ${ }^{2}$ \}
}

Program Studi Informatika, Universitas Muhammadiyah Sidoarjo, Indonesia ${ }^{1,2}$

\begin{abstract}
The growth of the furniture industry relies heavily on good marketing activities. In this digital and online era can be utilized in terms of marketing in the furniture industry. Toko 99 Mebel is one of the furniture stores that still use conventional transaction and order recording. So product marketing is less innovative and efficient. The purpose of this research was to build an android-based furniture sales application that added a QR Code scan feature that can be a new innovation in 99 furniture stores in marketing products. QR Code serves as a feature to display a description of the product to be ordered quickly. The method used is waterfall, useful to reduce errors in building applications. Testing in this application using the Black Box method, this test method is very important to test the fungisonality of the application as opposed to internal structure or work. With waterfall method and Black Box testing method in application development can be arranged well and appropriately. As well as being able to participate in the sale of 99 Furniture Stores, because it will further facilitate the process of selling furniture online via android smartphone so that it is expected to increase customer interest to buy furniture in 99 Furniture Stores.
\end{abstract}

Keywords - furniture; sales aplication; QR Code; android

\begin{abstract}
Abstrak. Pertumbuhan industri mebel sangat bergantung pada kegiatan pemasaran yang baik. Di era yang serba digital dan online ini dapat dimanfaatkan dalam hal pemasaran di industri mebel. Toko 99 Mebel merupakan salah satu toko mebel yang masih menggunakan transaksi dan pencatatan pemesanan secara konvensional. Sehingga pemasaran produk kurang inovatif dan efisien. Tujuan dari dilakukannya penelitian ini untuk membangun aplikasi penjualan mebel berbasis android yang ditambahkannya fitur scan QR Code yang dapat menjadi inovasi baru pada toko 99 mebel dalam memasarkan produk. QR Code berfungsi sebagai fitur untuk menampilkan deskripsi tentang produk yang akan dipesan secara cepat. Metode yang digunakan adalah waterfall, berguna untuk mengurangi kesalahan dalam membangun aplikasi. Pengujian dalam aplikasi ini menggunakan metode Black Box, metode uji ini sangat penting untuk menguji fungisonalitas aplikasi yang bertentangan dengan struktur internal atau kerja. Dengan metode waterfall dan metode pengujian Black Box dalam pembangunan aplikasi dapat tersusun baik dan tepat guna Hasil uji penggunaan terhadap beberapa responden $87 \%$ menyatakan sangat setuju bahwa antarmuka serta fungsionalitas berjalan dengan baik dan mudah untuk digunakan, dengan begitu penjualan pada Toko 99 Mebel akan lebih mudah dengan penjualan mebel secara online via smartphone android serta dapat meningkatkan minat pelanggan untuk membeli mebel di Toko 99 Mebel.
\end{abstract}

Kata Kunci - mebel; aplikasi penjualan; QR Code; android

\section{Pendahuluan}

Implementasi teknologi akan mengubah kehidupan sebagian besar penduduk Indonesia dari tahun ke tahun, semakin dimudahkannya dalam berbagai hal di kehidupan sehari-hari salah satu contoh dalam perkembangan ecommerce. Kondisi pertumbuhan industri e-commerce sekarang, meningkatkan jumlah pembeli secara online [1]. Disusul dengan semakin banyaknya industri memasarkan produknya dengan berbagai aplikasi penjualan online. Dampaknya dari perkembangan tersebut dapat meningkatkan dalam segi pemasaran sekaligus sebagai media promosi kepada konsumen. Teknologi yang sudah berkembang harus dimanfaatkan seefisien mungkin untuk membantu produsen maupun konsumen agar semakin mempermudah dalam proses jual beli.

Toko "99" Mebel yang berada di Kabupaten Sidoarjo, Jawa Timur ini merupakan salah satu Toko Mebel tradisional yang sudah lama berdiri. Dalam berbagai hal dilakukan dengan metode jual yang konvensional. Tradisional disini mempunyai arti sistem penjualan masih dengan bertemunya penjual dan pembeli secara langsung, begitu juga dengan pembukuan tentang pesanan yang ada masih menggunakan buku. Sehingga perlu inovasi baru untuk Toko Mebel tradisional dalam segi teknologi pemasaran secara mobile sebagai pendongkrak eksistensi industri mebel untuk terus berkembang[2]. Maka dari itu penelitian yang berjudul "Aplikasi Penjualan Mebel dengan Teknologi QR Code Berbasis Android" diharapkan dapat menjadi inovasi baru dan mempermudah dalam penjualan mebel di toko tersebut. 


\section{METODE}

\section{A. Aplikasi}

Aplikasi merupakan alat bantu yang diciptakan agar mempermudah dan mempercepat proses pekerjaan dan mempunyai artian bukan beban bagi penggunanya [3]. Aplikasi yang biasanya berupa perangkat lunak yang terdiri dari rangkaian beberapa perintah atau program yang dibangun untuk membantu pekerjaan manusia. Contoh aplikasi untuk jual beli (e-commerce), Pelayanan atau jasa ,maupun permainan. Hampir seluruh pekerjaan manusia bisa dilakukan dengan dibantu oleh suatu aplikasi.

\section{B. Penjualan}

Definisi dari penjualan merupakan kegiatan untuk mempertahankan bisnis perusahaan untuk tetap berkembang dan mendapatkan keuntungan atau laba yang diharapkan. Kata penjualan berarti proses aktivitas menjual, dimulai dari pematokan harga jual sampai distribusikan produk tersebut sampai ke tangan pelanggan (konsumen) [4].

\section{Mebel}

Mebel merupakan perabot rumah yang diperlukan, berguna maupun diminati. Tidak hanya untuk rumah mebel juga digunakan untuk melengkapi rumah, kantor, dan sebagainya. Kata mebel yaitu berasal dari kata movable yang berarti mudah dipindahkan contoh meja, kursi lemari dll. Untuk menunjang kebutuhan untuk tidur, menyimpan baju, meletakkan macam-macam barang. Mebel atau yang biasanya disebut furnitur ini terbuat dari material kayu, plastik, papan kayu, busa, kulit, sekrup, dll. [5]

\section{QR Code}

Quick Response Code atau yang sering disebut dengan QR Code merupakan barcode dua dimensi yang dikenalkan pada 1994 oleh Perusahaan asal Jepang yang bernama Denso Wave. Teknologi ini pertama kali digunakan pada pendataan inventaris perusahaan suku cadang kendaraan bermotor dan sekarang berkembang diimplementasikan ke dalam berbagai bidang bisnis dan jasa untuk kegiatan promosi dan marketing. Dasar pengembangan dari QR Code ini menyimpan data yang memungkinkan data tersebut dibaca dengan kecepatan tinggi [6]. QR Code telah banyak diimplementasikan dalam bentuk aplikasi QR Code Generator sehingga seseorang sangat mudah membuat QR Code yang berisi informasi dan mendapatkan informasi yang ingin diketahui dengan cara melakukan scanning atau pemindaian informasi melalui smartphone dengan aplikasi kamera.[7]

\section{E. Android}

Android merupakan sistem operasi yang diperuntukkan untuk telepon seluler. Basis Android adalah linux OS, platform tersebut masuk dalam kategori terbuka untuk para pengembang untuk membangun suatu aplikasi yang digunakan dalam berbagai macam piranti bergerak [8]. Fungsi yang sama seperti sistem operasi yang lain seperti IOS, Symbian, maupun Windows Phone.

\section{F. Teknik Pengumpulan Data}

a. Observasi

Teknik Pengumpulan data yang dilakukan penulis dengan cara pengamatan langsung di Toko "99" Mebel Kabupaten Sidoarjo untuk memperoleh data serta informasi yang nantinya digunakan dalam pembuatan aplikasi dalam penelitian ini.

b. Studi Literatur

Pencarian informasi dari berbagai studi pustaka dan literatur terpercaya seperti buku, jurnal, website dan literatur yang berkaitan dengan pembahasan pada penelitian ini. untuk menganalisa permasalahan yang terjadi.

c. Wawancara

Wawancara yang dilakukan penulis kepada pemilik Toko "99" Mebel untuk memperoleh informasi dan data yang dibutuhkan untuk mendukung perkembangan aplikasi ini.

\section{G. Metode Penelitian}

Membangun sebuah aplikasi dibutuhkan kerangka kerja yang sistematis agar aplikasi terselesaikan tepat waktu yang disebut juga SDLC (System Development Life Cycle) dan . Berbagai macam metode dalam SDLC, adapun metode yang digunakan dalam aplikasi ini yaitu metode Waterfall yang memiliki beberapa tahapan sebagai berikut : 


\section{H. Use Case Diagram}

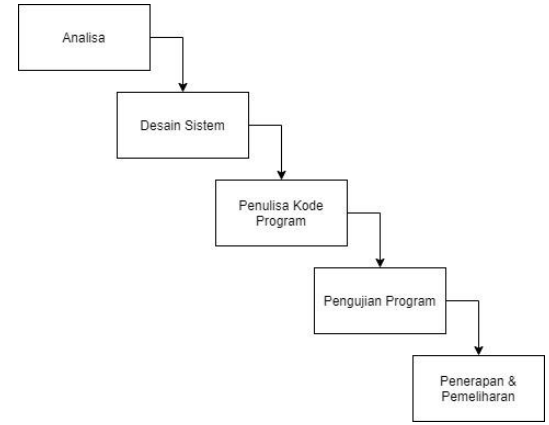

Gambar 1. SDLC Waterfall

Use Case Diagram yaitu perancangan model perilaku sistem yang akan dibangun dan menggambarkan interaksi antar pengguna dan sistem[9].Use case pada aplikasi ini mempunyai 3 aktor yaitu user, admin, dan kasir untuk registrasi dan melakukan pembelian hanya bisa dilakukan user, admin melakukan edit data pada basis data aplikasi ini, dan kasir hanya bisa melakukan konfirmasi pembayaran. Berikut tampilan Use case yang digunakan :

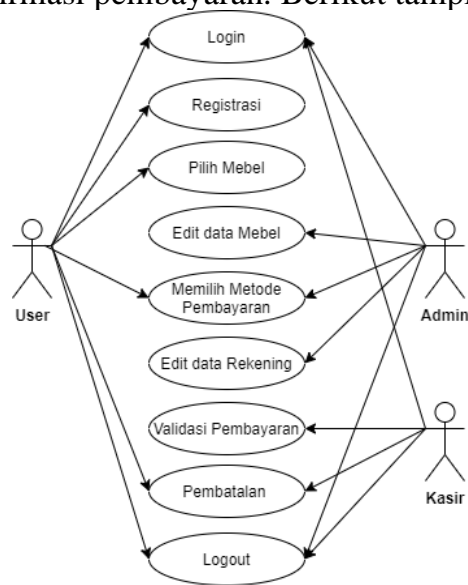

\section{Activity Diagram}

Gambar 2. Use Case Diagram

Diagram activity menjelakan alur aktifitas yang terdapat pada sistem aplikasi yang akan dibangun. Terdapat tiga macam activity diagram yaitu untuk user atau pelanggan, admin dan kasir. Activity diagram digambarkan seperti berikut activity:
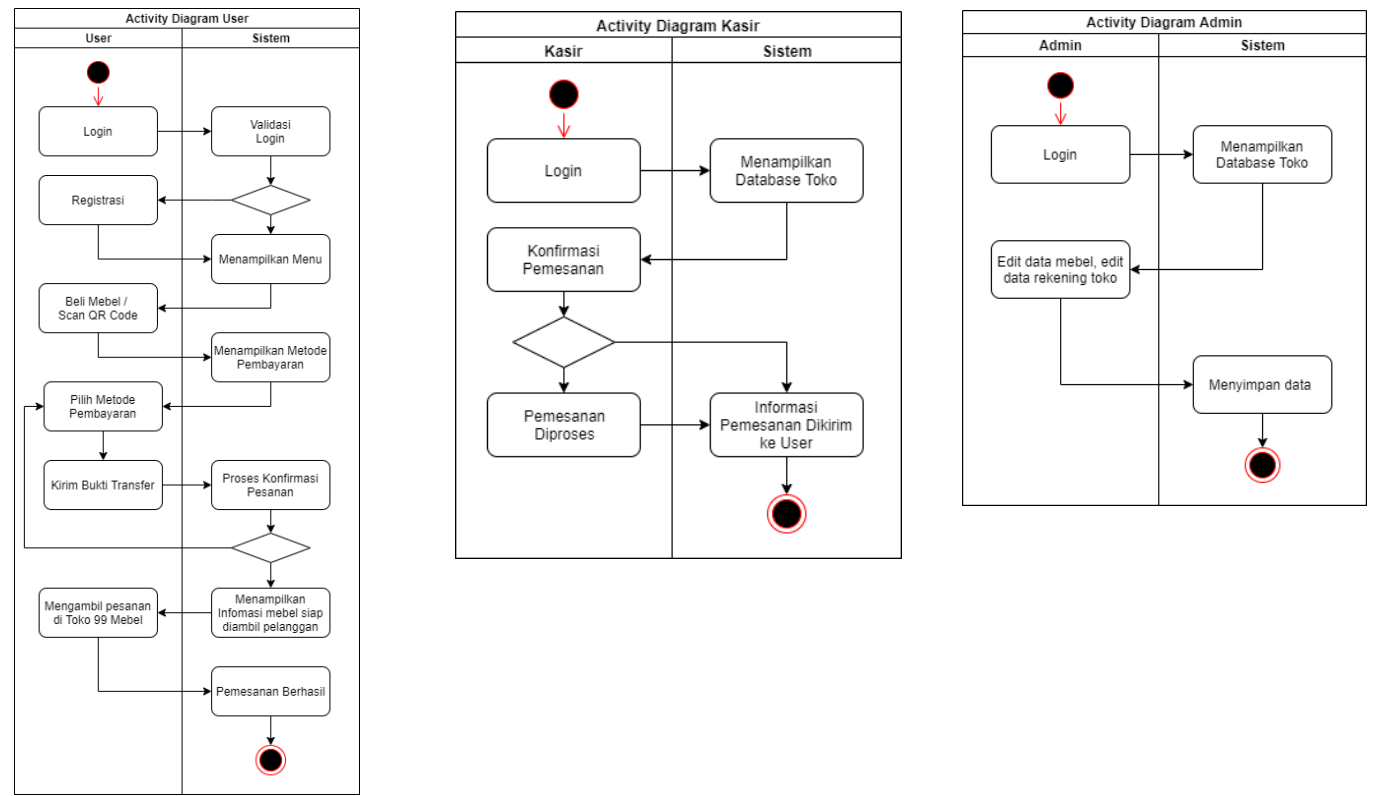

Gambar 3. Activity Diagram

\section{J. Entity Relationship Diagram}


ERD (Entity Relationshop Diagram) merupakan kumpulan simbol yang membentuk suatu hubungan antar entitas yang menjelaskan tipe dari entitas tersebut berupa data dari atributnya [10].Dalam perancangan aplikasi diperlukannya ERD guna mempermudah dalam analisa basis data pada sistem yang akan dibangun. Terdapat 5 entitas di ERD yaitu Pelanggan, Admin, Kasir, Transaksi, dapat dilihat pada gambar dibawah ini :

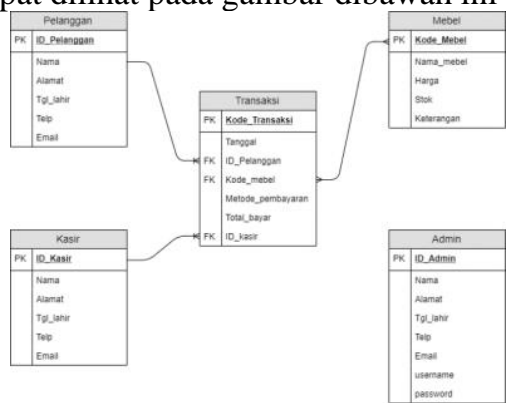

Gambar 4. ERD

\section{Hasil dan Pembahasan}

\section{A. Halaman Login}

Halaman login merupakan antarmuka pertama yang ditampilkan oleh aplikasi penjualan. Pengguna diwajibkan mengisi form username dan password yang telah diregistrasi sebelumya. Apabila pengguna masih belum terdaftar tekan daftar, tampilan akan berpindah ke halaman registrasi. Form registrasi berisi data diri yang harus diisi.

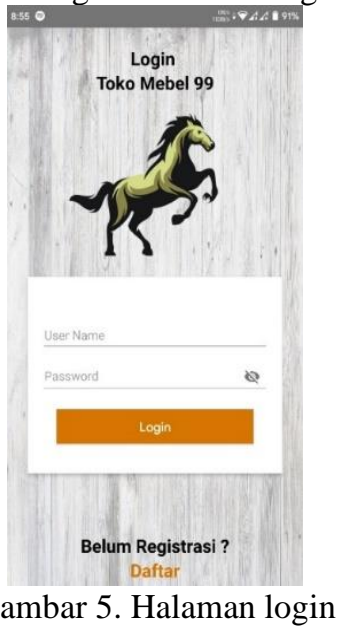

B. Halaman Beranda

Gambar 5. Halaman login

Pada halaman beranda pelanggan berisi beberapa menu yaitu profil untuk melihat data pelanggan, scan qr untuk menscan QR Code yang selanjutnya diarahkan ke deskripsi produk, menu katalog untuk melihat daftar produk yang dijual, menu status penjualan untuk melihat seluruh daftar pesanan yang telah dilakukan.

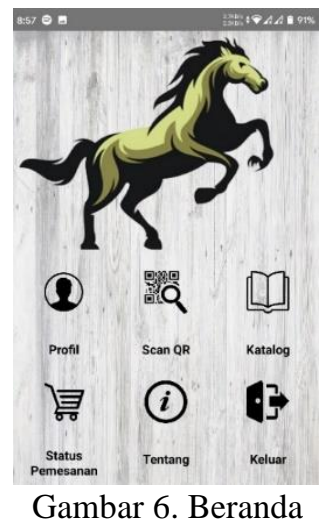

\section{Halaman Scan QR Code}

Halaman Scan QR merupakan fitur dalam aplikasi Toko Mebel 99 yang fungsi untuk memindah kode QR yang terdapat pada mebel yang akan dipesan, Kode QR tersebut berisi kode mebel yang sudah diinputkan ketika admin menambahkan produk kedalam halaman katalog. Berikut tampilan halaman scan QR Code. 


\section{Halaman Status Pemesanan}

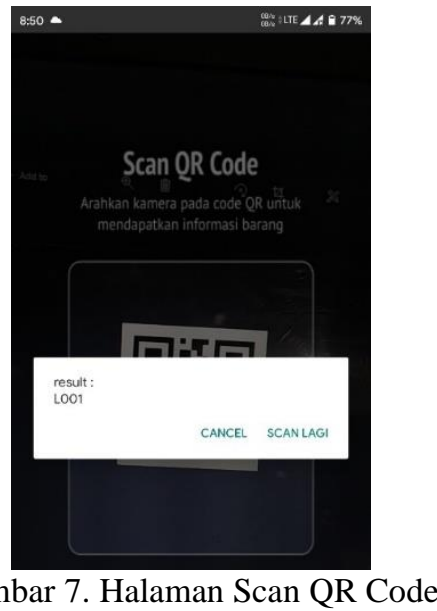

Halaman status pesanan merupakan antarmuka yang berisi seluruh pesanan yang dibeli oleh pelanggan. Informasi yang ditampilkan yaitu produk mebel, status pemesanan, serta bukti tranfer apabila telah melakukan upload bukti pembayaran. Berikut tampilan status pemesanan.

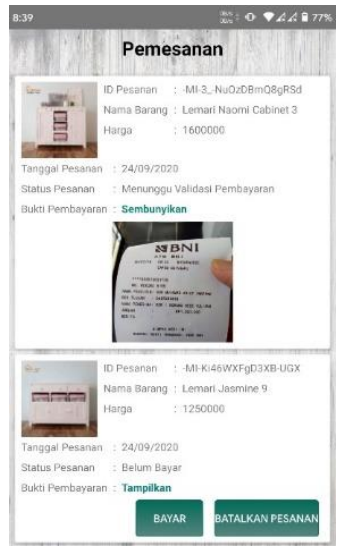

\section{E. Halaman Beranda Kasir}

Gambar 8. Halaman Katalog

Halaman beranda kasir merupakan halaman yang dikhusukan untuk admin, beberapa fitur yang dimiliki halaman ini adalah validasi terhadap pesanan pelanggan, menu pesanan berisi semua pesanan yang sedang dalam proses pembuatan mebel, untuk riwayat pesanan berisi record/ rekaman daftar pesanan yang masih berjalan dan yang telah selesai.

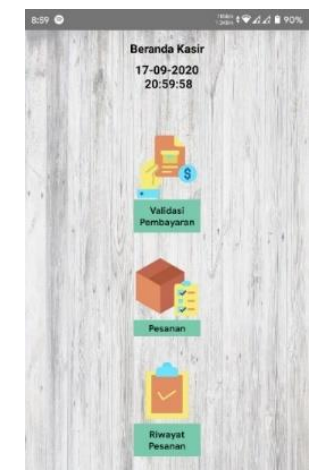

Gambar 9. Halaman Beranda Kasir

\section{F. Halaman Validasi Pembayaran Kasir}

Halaman validasi kasir yaitu tampilan yang berisi seluruh list pesanan pelanggan yang dalam proses validasi oleh kasir. Peran kasir disini untuk memvalidasi bukti pembayaran. Apabila bukti tersebut valid pesanan akan diteruskan ke proses pembuatan mebel. Apabila bukti tersebut tidak valid pesanan dibatalkan, pelanggan harus mengirim ulang bukti transfer. Berikut tampilan halaman validasi pembayaran pada gambar dibawah ini. 


\section{G. Halaman Beranda Admin}

Gambar 10. Halaman Validasi Pembayaran Kasir

Halaman beranda kasir merupakan antarmuka yang berisi fitur yang ditujukan untuk pengguna level admin. Beberapa fitur yaitu kelola barang untuk edit data produk, menu pesanan untuk memonitoring pesanan yang dilakukan oleh pelanggan, untuk metode pembayaran berisi data rekening pemilik toko mebel.

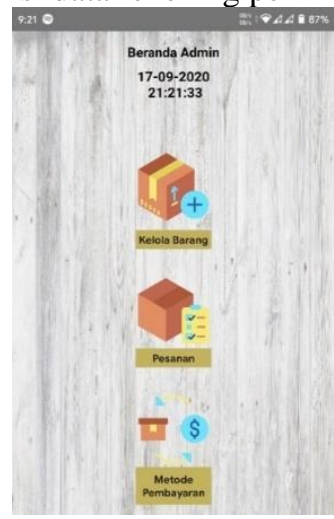

\section{H. Halaman Kelola Barang Admin}

Gambar 11. Halaman Beranda Admin

Halaman kelola barang admin merupakan halaman yang digunakan admin untuk menambah, update dan menghapus produk mebel.

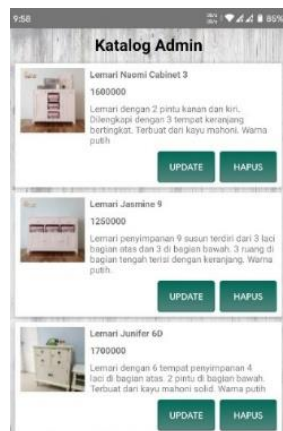

Gambar 12. Halaman Kelola Barang Admin

\section{KESIMPULAN}

Hasil dari pengujian dan tujuan dibuatkannya aplikasi penjualan mebel dengan teknologi QR Code pada Toko Mebel 99 berbasis Android, maka dapat disimpulkan sebagai berikut :

1.Aplikasi yang telah dibangun dengan mengimplementasi teknologi QR Code sudah berjalan dengan baik dan dapat menjadi inovasi baru pada Toko Mebel 99 dalam penjualan mebel.

2.Aplikasi penjualan mebel ini memudahkan pelanggan Toko Mebel 99 melakukan pemesanan mebel serta membantu pihak toko dalam memberikan informasi deskripsi produk ke pelanggan .

3.Pengujian terhadap fungsionalitas berjalan dengan baik serta UAT telah dilewati dengan mendapat hasil rata-rata $87 \%$ responden menyatakan sangat setuju antarmuka, fitur serta fungsionalitas berjalan lancar dan sesuai yang diharapkan. 
Sesuatu yang sangat dibutuhkan guna pengembangan aplikasi berkelanjutan adalah saran untuk penambahan fitur baru yang perlu ditambahkan seperti berikut :

1.Penambahan fitur kategori produk.

2.Penambahan fitur notifikasi ketika status pemesanan berubah.

3.Penambahan fitur chat antar penjual dan pembeli

Dari saran penambahan fitur diatas diharapkan untuk selanjutnya aplikasi ini dapat selalu diperbarui karena penulis sadar masih perlu perbaikan lagi dalam aplikasi ini guna untuk mengikuti perkembangan pada dunia aplikasi perangkat lunak berbasis Android.

\section{UCAPAN TERIMA KASIH}

Pelaksanaan penelitian ini tidak sertamerta terselesaikan dengan baik tanpa adanya pihak lain yang terkait andil dalam penelitian ini. Ucapan terimakasih kepada pihak Toko Mebel 99 Sidoarjo sudah menjadi objek dalam penelitian. Dengan adanya penelitian ini semoga kedepannuya Toko Mebel 99 lebih efisien dan inovatif dalam pelayanan penjualan mebel.

\section{REFERENSI}

[1] Donnal, Andri. 2018 Jumlah Pembeli "Online" Indonesia Capai 11,9 Persen dari Populasi di https://ekonomi.kompas.com/read/2018/09/07/164100326/ jumlah-pembeli-online-indonesia-capai-119-persendari-populasi (Diakses 28 Oktober 2019)

[2] Kerjo. 2019. Potensi Industri Mebel Indonesia di https://news.detik.com/adv-nhl-detikcom/d-4477488/potensiindustri-mebel-indonesia. (Diakses 31 Oktober 2019)

[3] EMS, Tim. 2013. Android All in One. Jakarta: PT. Elex Media Koputindo

[4] Basu Swastha, I. (1990). Manajemen Pemasaran Modern. In Liberty, Yogyakarta. https://doi.org/10.1017/CBO9781107415324.004

[5] Anonim. 2019. Kamus Besar Bahasa Indonesia [Online]. Tersedia di : https://kbbi.kemdikbud.go.id/entri/mebel. (Diakses 1 November 2019)

[6] Rouillard, J. (2008). Contextual QR codes. Proc. - The 3rd Int. Multi-Conf. Computing in the Global Information Technology, ICCGI 2008 in Conjunction with ComP2P 2008: The 1st Int. Workshop on Computational P2P Networks: Theory and Practice. https://doi.org/10.1109/ICCGI.2008.25

[7] Safaat H.Nazruddin.2012.Pemrograman Aplikasi Mobile Smartphone dan Tablet PC berbasis Android. Bandung: Informatika

[8] Firly, Nadia. 2019. Android Application Development For Rookies With Database. Jakarta: PT. Elex Media Koputindo

[9] Sholiq . 2006.Pemodelan Sistem Informasi Berorientasi Objek dengan UML. Yogyakarta: Graha Ilmu

[10] Munif, Abdul. 2013, Basis Data. PPPPTK Boe Malang. Malang: Kementrian Pendidikan \& Kebudayaa 